of the individual attempting the suicide. Third, the real trigger for the attempt may never be known, even to the family members, if there is no 'hard copy' suicide note. It would be interesting to know the incidence of 'electronic' suicide notes and to ascertain whether it is gaining popularity among patients.

KALLUR SURESH, Registrar, and SEAN LYNCH, Senior Lecturer and Consultant Liaison Psychiatrist, St James's University Hospital, Beckett Street, Leeds LS9 7TF

\section{Community psychiatry in the RAF: an evaluative review}

Sir: Reid identified "two omissions of pertinent fact" (Psychiatric Bulletin. December 1997, 21, 786-787) in my paper on Royal Air Force (RAF) community psychiatry (Hughes, 1997). First, he mentioned the changes occurring in the RAF at the time of my study. In an earlier draft (seen by Reid) I agreed that uncertainty in the RAF may have increased the rate of psychiatric referrals. In which case, however, the need for RAF community psychiatrists in 'normal' times would be diminished. But we could both be wrong, because it could be that psychiatric referrals go up after a period of stress.

Second, Reid pointed to changes in the RAF medical services themselves. I referred to these changes in the opening sentence of my paper. How (and whether) the changes in medical services affected psychiatric referrals would need to be established before this became a pertinent fact.

Reid asserted (without references) that audit has shown RAF community psychiatric teams "to be both effective and efficient". He may be thinking of those studies (some of which I cited) from a decade or more ago, but these would seem now to be irrelevant because of the changes already mentioned. The only published study of RAF community psychiatry as recently practised is mine. I should be pleased if it stimulated further research.

This was, indeed, the intention of the paper to stimulate discussion. As shown by my closing sentences, I am certainly not unsympathetic to military psychiatry. At a time when the armed forces minister has acknowledged the parlous state of the defence medical services, it would be sensible to seek out those areas in which military psychiatrists have something unique to offer (e.g. research into psychological aspects of trauma). Such areas should then be actively fostered. But it may be possible to manage day-to-day psychological morbidity in the RAF community, as I suggested, without RAF psychiatrists.
Hughes, J. C. (1997) Community psychiatry in the RAF: an evaluative review. Psychiatric Bulletin. 21, 418-421.

Julian C. Hughes, Senior Registrar, Fair Mile Hospital, Oxford, OX10 9HH

\section{Youth attitudes to services in Ireland}

Sir: Ninety-three arts students at University College Cork completed a questionnaire on the impact of suicidal behaviour on their lives. The first question asked whether they would seek help if they were in trouble, particularly if they had persistent ideas of self-harm. Friends and family were the most popular options but almost half did not know where they would turn. In response to a second question, inquiring as to what organisations would provide acceptable help, 47 suggested the Samaritans. St Patrick's Private Psychiatric Hospital in Dublin was the only psychiatric service mentioned and general practitioners and local medical services were not suggested at all.

The most striking message of this study is the lack of information about available services among even a relatively advantaged group of young adults and the apparent reluctance of many to seek help outside of their immediate social cricle when distressed or in danger of selfharm. This calls into question the suitability of available services for the group who appear, on the basis of the most recent statistics, to need them most. This is not just a local or Irish problem; similar poor uptake of services bedevil attempts to address this problem elsewhere (Schaffer et al, 1988). Would there be a better uptake of services and a reduction in morbidity and mortality, if the services already available for the young were marketed differently?

SCHAFFer, D. GARLAND, A. GouLd, M. et al (1988) Preventing teenage suicide: a critical review. Joumal of the American Academy of Child and Adolescent Psychiatry, 27, 675-687.

HELEN KEELEY and MiCHAEL J. KELleHER, National Suicide Research Foundation, 1 Perrott Avenue, College Road, Cork, Ireland

\section{Elderly peoples' views of the Care Programme Approach}

Sir: Rotherham District General Hospital has a catchment area of 38000 people over 65 . A recent survey found that 33 of these are on level 2 of the CPA. though two were found to be dead. Of the remainder, 16 subjects were suffering with functional illnesses and 15 with dementia. All of the functionally ill patients signed their care programmes. The keyworkers were community psychiatric nurses, social workers, community 